\title{
1. Primal Screens
}

\author{
Francesco Casetti
}

\begin{abstract}
In a polemical stance against current media archaeologies, Francesco Casetti re-reads what film theories consider 'proto-screens'-respectively Athena's shield, which Perseus converted to a tool of warfare; Boutades's wall, on which his daughter fixed her lover's shadow; and Alberti's window, which the artist transforms into a perspectival matrix. While these narratives are just that — narratives - they reveal many of our present-day assumptions and priorities. In particular, they uncover how screens do not exist as such. A screen becomes a screen thanks to an assemblage of elements and within a set of operations in which it can perform specific functions. Furthermore, screens are not only optical devices; they are environmental media. The dispositives illustrated by the three narratives heavily imply space: while exploiting environmental components, they address hands, legs, distances, and alignments as much as they move eyes and sights.
\end{abstract}

Keywords: Assemblage, Media Archaeology, Dispositif, Myth

\section{Prefigurations}

Media studies often falls prey to a strange fascination. The more frantic the transformations of the media landscape, the more theorists feel the need to cast a retrospective look at the media past. This historical view is expected to capture not only the story of a single medium but also its place in a longer lineage: its origins and previous instantiations. Hence the current boom of media archaeology, whose tasks and methods have been voiced especially by Erkki Huhtamo and Jussi Parikka — and in a more critical mode, by

Buckley, C., R. Campe, F. Casetti (eds.), Screen Genealogies. From Optical Device to Environmental Medium. Amsterdam: Amsterdam University Press, 2019 DOI 10.5117/9789463729000_CHO1 
Thomas Elsaesser. ${ }^{1}$ Beyond offering readers the pleasure of its historical reconstructions, media archaeology is symptomatic of the desire to find roots and continuity in an age of breathless change.

This fascination with ancestry is not new: early film theory experienced it extensively. In an attempt to understand film's amazing success, many commentators argued for the medium's ancient pedigree. It suffices to mention the Czech critic Václav Tille, who in 1908 opened his foundational essay 'Kinema' by writing about shadow theatre; the American poet Vachel Lindsay, who in 1915 devoted a famous chapter of his The Art of the Moving Picture to hieroglyphics; and the Italian musicologist Sebastiano Arturo Luciani, who in 1916 connected the new art with the Roman pantomime. ${ }^{2}$ As in many recent media archaeologies, early film scholars appealed to a principle of likeness ('what is similar belongs to the same family') and a principle of causality ('what comes first is the source of what comes later') in order to find how film was foreshadowed. ${ }^{3}$

The psychological need for prefiguration is not without reasons: at the very least, it confers the prestige usually granted by a 'myth of origin'. ${ }^{4}$ Yet, if we go back to the Foucauldian idea of archaeology, and even more to his reinterpretation of Nietzche's genealogy, 5 the idea of prefiguration is simply nonsensical. Genealogy looks at the way a dispositive emerges: at the breaks and rearrangements that its emergence implies and the peculiarities that characterize every emergence. In this framework, according to Foucault,

...to follow the complex course of descent is to maintain passing events in their appropriate dispersion; it is to identify the accidents, the minute deviations - or conversely, the complete reversals - the errors, the false appraisals, and the faulty calculation that gave birth to those things that continue to exist and have value for us. ${ }^{6}$

\footnotetext{
* This contribution has been developed in the framework of my ongoing conversation with Bernard Geoghegan aimed at a systematic exploration of what we call 'screenscapes'. An early version of this essay was discussed at the ICI-Berlin: my thanks to Christoph Holzhey and Manuele Gragnolati. For substantive feedback on early drafts, thanks to Mal Ahern. This essay is dedicated to Gary Tomlinson.

1 See Huhtamo and Parikka, 2011; Parikka, 2012; Elsaesser.

2 Tille, pp. 71-91; Lindsay, pp. 75-76; Luciani, pp. 1-2.

3 An indicative example of recent screen archaeology using the principle of likeness - in a volume that is nevertheless a very useful collection — can be found in Moure, 2016.

4 Frederic Jameson speaks of the 'prestige of a "myth of origins"'. Jameson, p. 174.

5 See Foucault, 1972, 1997.

6 Foucault, 1977, p. 146.
} 
We are not dealing here with a family tree; on the contrary, we must cope with a composite landscape, a field characterized by discontinuity, singularity, and divergence. ${ }^{7}$ Ancestors do not have much room on this field.

The only way of conceiving of a prefiguration, then, is to admit that it is an account of origins that emerges only after the historical fact of that emergence has taken place. A prefiguration is a retrospective fantasy: it is something that we identify because a dispositive already exists, and it is something we use as an explanation for that dispositive's emergence. It is a reconstructed 'pre-' that we project onto an asserted 'post-'.

Why, then, give space to prefigurations? Because their paradoxical status can be a resource. A prefiguration highlights what we perceive as crucial in a dispositive - so crucial that we feel we must search the history and pre-history of that dispositive for the original occurrence of its defining characteristics. A prefiguration makes material and perceptible our own concerns about a medium, and consequently it uncovers that medium's oftenimplicit social meaning. In this sense, the idea of a medium's pre-history can help us gain a self-reflexive vision. At the same time, a prefiguration is an emergence in its own turn; as such, it is always marked by a singularity. Yet, once we assume — at least tentatively — that it is a pre-figuration, its singularity no longer coincides with a simple uniqueness. Occurrences become re-occurrences, in which an event recurs while keeping its nature of event and at the same time establishing connections that go beyond formal likeness or historical causality. In this sense, the idea of an anteriority can help us gain a perspective that, while refusing easy shortcuts like family trees, nevertheless preserves the idea of a certain communality.

In the next pages, I will tackle three examples of the screen's prefiguration, testing them as potential resources in the genealogy of the screen. Often considered 'primal scenes' in a long history of cinema, these three examples have satisfied film theorists' appetite for origins and archetypes. Here, I will analyze them instead in their distinctiveness, underscoring the ways in which each of them deals with dispositives that we can recognize expost facto as connected with screens. As a consequence, the three examples reveal the contexts, the sets of operations, and the basic conditions that allow a screen - whatever its materiality and substance — to perform as a screen. Seen within the framework of a non-causal, non-linear, and non-teleological history, these prefigurations do not tell us anything about the screen's actual

7 '[Genealogy] must recall the singularity of events outside of any monotonous finality; [...] it must be sensitive to their recurrence, not in order to trace the gradual curve of their evolution, but to isolate the different scenes where they engaged in different roles.' Foucault, 1977, pp. 139-140. 
lineages; instead, they suggest the playground on which screens emerge. They do not delineate the screen's ideal typology; instead, they enumerate the screen's affordances. They do not define the screen's essence but illustrate its process of becoming-screen.

\section{Athena's shield}

Perseus's myth enjoyed widespread circulation in the classical world: it is present in Homer and Hesiod, but it found its most complete and best-known version in Ovid's Metamorphoses. ${ }^{8}$ More recently, Jean Pierre Vernant has offered an expanded version of the myth that includes its multiple variants. ${ }^{9}$

In short, the story is the following. Sent by King Polydectes, Perseus travels in search of Medusa-one of the three Gorgons, the only one who is mortal but also the most terrible of all. Her hair is made of serpents; her gaze transforms everybody who meets it into stone. Perseus must kill Medusa and behead her: this is the deed assigned to him. On his way, Perseus avoids the threat posed by the three Graeae, stealing the one eye they share between them. He meets the Nymphae who give him winged sandals that let him fly, a mask that makes him invisible, and a sack in which he will hide the Gorgon's head once severed, so as to cover her murderous eyes. He adds these objects to a shield that Athena lent him and to a scythe that he received from Hermes.

When Perseus finally reaches Medusa, he approaches her while she sleeps. He does not look at her directly but gazes at her reflection on the polished surface of the Athena's shield.

In the mirror of his polish'd shield

Reflected saw Medusa slumbers take

And not one serpent by good chance awake. ${ }^{10}$

Thanks to this ruse, Perseus avoids being stoned by Medusa; he comes upon her and he beheads her with the Hermes's scythe, thus fulfilling King Polydectes's request. And yet Medusa's head preserves its nefarious power: back in Polydectes's court, when Perseus lifts the disembodied head out of

9 Vernant, 2001, pp. 173-184.

10 Ovid, IV, lines $782-784$. 
the sack, he petrifies the king and the courtiers.Why did Medusa become a monster? She had once been a beautiful woman with golden ringlets, but after Neptune seduced her in a temple dedicated to Athena, the angry Goddess transformed her golden hair into snakes. Perseus bestows Medusa's head upon Athena in recognition of her help: eventually, the severed head adorns the Goddess's breastplate, as a sign of power and as admonition to her enemies. ${ }^{11}$

Most of the interpretations of Perseus's myth revolve around Medusa's paralyzing gaze. Explications abound. The Gorgon is the symbol of castration that terrifies the little boy when he looks at female genitals for the first time and realizes that the possession of his penis cannot be taken for granted. ${ }^{12}$ She recalls the animals that reproduce on their skins images of eyes in order to scare and deceive their attackers. ${ }^{13}$ She is a hint of the source of the evil-eye superstition that we meet in so many cultures. ${ }^{14}$ She is the absolute otherness that we are unable to incorporate into our world. ${ }^{15}$ It was the film theorist Siegfried Kracauer who shifted his attention from Medusa's face to Athena's shield. In the last pages of his Theory of Film, he claims that the shield is a direct ancestor of the movie screen. Kracauer writes:

The moral of the myth is, of course, that we do not, and cannot, see actual horrors because they paralyze us with blinding fear; and that we shall know what they look like only by watching images of them which reproduce their true appearance [...] Now of all the existing media the cinema alone holds up a mirror to nature. Hence our dependence on it for the reflection of happenings which would petrify us were we to encounter them in real life. The film screen is Athena's polished shield. ${ }^{16}$

Kracauer's interpretation is undoubtedly compelling. Yet how can a polished shield become a screen? What allows us to assign it this function and this

11 'Yet above all, her length of hair, they own, /In golden ringlets wav'd, and graceful shone. /Her Neptune saw, and with such beauties fir'd, /Resolv'd to compass, what his soul desir'd. / In chaste Minerva's fane, he, lustful, stay'd, /And seiz'd, and rifled the young, blushing maid. / The bashful Goddess turn'd her eyes away, /Nor durst such bold impurity survey; /But on the ravish'd virgin vengeance takes, /Her shining hair is chang'd to hissing snakes. /These in her Aegis Pallas joys to bear, /The hissing snakes her foes more sure ensnare, /Than they did lovers once, when shining hair.' Ovid, IV, p. 139.

12 Freud, 1993, pp. 212-213.

13 See Caillois, 1960.

14 See Siebers, 1983.

15 See Vernant, 1985.

16 Kracauer, 196o, p. 305. 
status? And what are the consequences of doing so? I will re-read the myth of Perseus with the screen in mind, focusing my attention on the key elements at stake.

First, Athena's shield is part of a collection of objects (including a scythe, a sack, a mask, and winged sandals) that Perseus brings with him and which orient his actions. They are gifts he received from gods or demi-gods, but they were not specifically conceived for a duel with the Gorgon. Under the pressure of events, Perseus converts them into tools that serve a new purpose. The shield becomes a mirror in the same way that the scythe becomes a sword, and a bag is transformed from a container into a disguise. In this way, these objects enter a sort of complex that allow Perseus to face the situation. They congregate and interact: they form a dispositive - or, better, an assemblage, to borrow the term Deleuze used to describe a coalescence and interplay of components. ${ }^{17}$

The emergence of an assemblage responds to what is happening, and it arises from what is available. Perseus's condition presents some threats and some opportunities: the hero must reckon with the former and use the latter. He must organize what is at hand and transform these objects into weapons, and so accomplish his task and survive. From this point of view, an assemblage relies on contingency and at the same time on conjuncture. It takes shape and gives shape to its components according to the chances and the affordances offered by a situation. Yet, once established, an assemblage provides a persistent framework within which one can cope with reality and reflexively recognize events. In short, it becomes a recognized space of mediation.

In this overall picture, the conversion of Athena's shield merits further explanation. The shield is typically a barrier behind which soldiers seek safety. Here, it changes its primary function: it is no longer supposed to intercept the enemies' blows; on the contrary, it has to provide a new kind of sight-indirect, yet capable of orienting the bearer in the battlefield. It no longer hides; it shows. It is still a technology of warfare more than it is a mirror in a conventional sense-in ancient Greek culture, mirrors were feminine and feminizing tools — nevertheless, it shifts from being a rejecting surface to a reflecting surface. ${ }^{18}$ It protects not because it keeps

17 The term assemblage is the English translation of the original French term agencement, yet it fully recovers the meaning of the original word. See Deleuze. For a discussion on the appropriateness of the English term, in contrast with the term apparatus, see Casetti, 2015, pp. 78-81

18 For a discussion of the mirror as feminine tool - and a tool that feminizes men who use it-see Frontisi-Ducroux and Vernant, 1997, p. 53; for Athena's shield as an improper mirror, and as an arm, see ibid., p. 70. 
the world separated, beyond the barrier, but because it replicates the world and consequently provides for its user a visual control of the situation. It grants a safe look, as Kracauer appropriately highlights.

But the conversion of the shield into an optical device is not without cost. From now on, Perseus's victory depends on what his eyes are able to capture as much as on what his arm is able to reach. It is not just the primacy of the sight that is established; it is a new confidence in visual data. Such a dependence on visual data recalls the process of 'visualization' that, according to Bruno Latour, so deeply transformed Western culture from the sixteenth century onward. ${ }^{19}$ It is at the climax of this process that the word 'screen' changed its main connotation. From denoting a protection against fire or air, or a divide that splits a room, or a filter that sieves grain, the term 'screen' begins to designate in the early nineteenth century, in connection with the emergence of the Phantasmagoria, a surface that hosts impermanent images. ${ }^{20}$ If there is a possible similarity between Athena's shield and the screen, it rests on such a conversion more than on some physical or functional similarity: Athena's shield also shifts from one connotation to another in the framework of an assemblage.

What kind of sight does the polished shield provide? Not only an indirect view but also a fragmentary one. Perseus barely has a whole and stable picture of the scene, even though the convex surface of the shield can provide enlarged visions. Moving forward, he must explore his surroundings, focus on the different elements within them, and then connect these in his mind. This is the only way he can get an idea of his context and therefore perform his action. Ovid offers insight into this behavior when he describes Perseus first approaching his target, then discovering Medusa asleep, and then finally checking the snakes on

19 See Latour, 1986.

20 I found two early occurrences of the word's new meaning in two notices referring to the Phantasmagoria's patent granted to Paul De Philipsthal on 26 January 1802, respectively published in the Cobbett's Political Register (p. 1053) and in The Monthly Magazine (p. 488). The two notices read 'transparent screen', while, quite curiously, the text of the patent published a few months before in The Repertory of Arts and Manufactures (p. 303-305) reads 'transparent body'. The substitution of the old term with the new-authorized by the fact that in the Phantasmagoria the screen had to hide the projector, before hosting the projected images - allows us to detect the time and context in which the visual connotations of screen emerged. The OED signals two later occurrences of the word, dated 1810 and 1846 , respectively referred to as the Phantasmagoria and magic lantern. See The Oxford English Dictionary, XIV, p. 722. 
her head. ${ }^{21}$ The shield gives back the world bit by bit, and Perseus must literally reconstruct it from these fragments. This kind of sight prompts two consequences. First, a direct encounter with Medusa would elicit not only the terror tied to an absolute threat but also the awe tied to a radical otherness. It would provide the freezing experience of the sublime. By using a screen as a tool for the progressive reconstruction of a situation, Perseus eliminates this possibility. The shield transforms perceptual awe into a set of operations aimed at appropriating the object; it turns the sublime into a spectacle at hand. Second, while Athena's shield details the surrounding reality, it never reflects Perseus's face. Unlike Narcissus, our hero does not have access to his own image. A look that progressively reconstructs a situation offers an answer to such a lack: Perseus can see his reflection through his own deeds. He can identify himself in the ongoing position that he occupies on the battlefield and in the ongoing effects of his action.

The myth does not end with Perseus's victory. There is a sort of coda that sees another assemblage emerge - and another conversion occur. Medusa's head becomes the adornment of Athena's breastplate. Consequently, the reflection on the surface of the shield is transformed and substituted by an emblem tied to another material support: a corset. Instead of a temporary mirrored image, we have now a permanently retained icon. And instead of a war machine, we have a piece of ceremonial regalia. Athena's statue, sculpted by Phidias, and which long stood on the Parthenon in Athens, epitomizes this last instantiation: the statue included both the shield and the head, and they represented a meaningful 'memento' of the goddess's deeds. ${ }^{22}$

At this point, the lesson imparted by Athena's shield is quite clear. No element, including a screen, is given as such: it becomes what it is through a process that often implies the conversion of an object into a specific tool. This process of becoming-screen always takes place in the context of a dispositive — or better, of an assemblage — whose constitution responds to both the contingencies and the conjunctures of a situation. Assemblages

21 'What wasteful havock dire Medusa made. /Here, stood still breathing statues, men before; /There, rampant lions seem'd in stone to roar. /Nor did he, yet affrighted, quit the field, /But in the mirror of his polish'd shield /Reflected saw Medusa slumbers take, /And not one serpent by good chance awake. / Then backward an unerring blow he sped, /And from her body lop'd at once her head.' Ovid, IV, p. 138.

22 'The statue of Athena is upright, with a tunic reaching to the feet, and on her breast the head of Medusa is worked in ivory. She holds a statue of Victory that is approximately four cubits high, and in the other hand a spear; at her feet lies a shield and near the spear is a serpent.' Pausanias, p. 125 . 
offer a framework for perceiving a situation and performing an action; optical assemblages do so through the production and circulation of visual data. Finally, an assemblage is always ready to yield room to another assemblage: its components can be re-drawn and re-defined - they can undergo another 'becoming'.

\section{Butades's wall}

The legend is seemingly simple and undoubtedly seductive. Pliny the Elder tells it in the Book 35 of his Natural History.

Butades, a potter of Sicyon, was the first who invented, at Corinth, the art of modelling portraits in the earth which he used in his trade. It was through his daughter that he made the discovery; who, being deeply in love with a young man about to depart on a long journey, traced the profile of his face, as thrown upon the wall by the light of the lamp. Upon seeing this, her father filled in the outline, by compressing clay upon the surface, and so made a face in relief, which he then hardened by fire along with other articles of pottery. This model, it is said, was preserved in the Nymphæum at Corinth, until the destruction of that city by Mummius. ${ }^{23}$

Mixing nighttime desire, a sexual encounter, and a father's intervention, Pliny depicts an intense primal scene. ${ }^{24}$ It is not by chance that the legend has exerted a persistent seduction on writers, art historians, painters, and photographers. ${ }^{25}$ As Maurizio Bettini claims, it is an archetype for the recurring narratives about love portrayed - and, accordingly, about our love for portraits. ${ }^{26}$ In his Brief History of the Shadow, Victor Stoichita describes the daughter's attempt to 'capture' the image of her lover in order to both rehearse his death and keep him 'upright' and 'alive' in a sort of erotic exorcism and propitiatory practice. Once the young man falls on the battlefield, the portrait that the father molds provides a 'duplicate' that, differently from the 'specter' on the wall, preserves in some way both a

23 Pliny the Elder, 35: 43 .

24 It is not the first time that Pliny mentions the projected shadows. See in particular Pliny the Elder, 35:5, where at stake there is the origin of painting. Here the narrative moves to the origin of portraiture, and it regards not only the figurative arts but also the plastic arts.

25 Jacques Derrida 1993 refers to paintings on the topic by Joseph Benoit Suvee and Jean-Baptist Reignault.

26 See Bettini, 1999. 
body and a soul. ${ }^{27}$ Despite the wealth of components in the story, its core is the projected shadow-hence its link with film theories. Though film scholars barely mention the legend, there is a repeated tendency to trace the origin of cinema to a fascination with projected shadows. It is what Václav Tille states in his 1908 essay. ${ }^{28}$ In 1956 , the French sociologist Edgar Morin resumes the argument in a brilliant analysis of film's anthropological roots. ${ }^{29}$ Pliny's legend thus offers a background to film theory.

Yet is not just the shadow that matters. Once again, we must look at the assemblage of tools, practices, and environment in which the shadow emerges. It is in this framework that we can understand how the shadow becomes present and why this tale of the origin of portraiture can elucidate the way in which screens emerge and work.

Looking at the scene, the first elements that come to the fore are the lamp from which the light emanates, the lover's face that intercepts the light, and the wall on which the lover's silhouette is outlined. The shadow exists because of them: literally, it is the product of a source of light, an obstacle that halts the light, and a surface that makes the shadow visible. Such a complex of elements implies a cogent spatial arrangement. Indeed, in order to produce a shadow and to cast it on a surface, the lamp, the face, and the wall have not only to coexist in the same space; they must also be positioned each in connection with each other, aligned on the same axis. The dispositive, or the assemblage, becomes spatial: in a word, it becomes an installation.

Within this spatial assemblage, we can recognize a set of operations that, quite paradoxically, work in pairs. On the one hand, there is an act of casting: the lamp casts a light, while the lover's face casts a shadow. The two actions have a different cogency. The lamp can be substituted with other sources, including the sun: not by chance, Quintilian's version of the legend stages the scene in broad daylight, ${ }^{30}$ and some of the most famous

27 Stoichita, 1997, pp. 16-20. Stoichita also compares Pliny's story with consonant narratives by Atenagoras, Quintilian, and especially Plato.

28 'The shadow is, of course, a very brittle and ephemeral material to use for artistic creation, yet its very versatility, volatility, swiftness, and malleability allow for the extraordinary powerful flowering of human fantasy, and the intricate and complex preparation required by the material creates a space for the boldest of compositions.' Tille, 2008, p. 89 .

29 'There remains, in our childhood development, a stage of fascination with shadows, and our parents' hands do their best to represent wolves and rabbits on our walls. There remains the charm of shadow theaters, known to the Far East. There remain the terror and anguish that the shadow can arouse - and that the cinema has admirably been able to exploit, in the same way it has been able to make good use of the charm of the mirror.' Morin, p. 29.

3o Quintilian, X:ii, 7. 
paintings inspired by Pliny's story do the same. ${ }^{31}$ Conversely, the lover's face is unique: it is precisely his silhouette, and nobody else's, that will ignite the next steps of the story. On the other hand, there is the act of intercepting: the lover's face intercepts the light, while the wall intercepts the shadow. Once again, the paired actions are similar, yet different. The face halts what is intercepted; the wall retains it. The former filters, the latter hosts. Playing with the polysemy of the word 'screen', we can say that the face is a screen that obstructs, while the wall is a screen that retains. Butades's legend states that the two aspects can be synchronized: an obstruction coexists and interacts with a retention. ${ }^{32}$

This complex set of correlations reveals the assemblage's orientation: in Pliny's story, the situation aims not simply at reflecting images but moreover at projecting them. A reflection, like the one we met in Athena's shield, requires just a surface that accommodates preformed images. A projection, instead, entails the facts of aiming towards a target, determining what is to be thrown, and throwing it towards the target: it implies a sophisticated form of ballistics. The connection between casting, filtering, and retaining satisfies these conditions. The wall (the screen) aggregates a set of practices. That said, reflection and projection tend to overlap: both are considered attributes of a screen. Not by chance, and from the very beginning, the screen has been identified in both of these ways, and recursively: as both a projective and a reflexive tool. ${ }^{33} \mathrm{Kept}$ in reserve, the difference nevertheless resounds.

Let's go back to Pliny's legend: the projection has a spectator. Butades's daughter looks at the shadow on the wall, then at her lover, again at the wall. She intervenes. She draws on the wall the outlines of her lover's profile. Her gesture is elicited by a desire but also by a fear: she is afraid the young man is going away. Hence the lines on the wall: they will amend a loss by granting a permanence, even though in effigy. This attempt at retaining the object of love - and at protracting, symbolically, an act of (carnal)

31 See, for example, Jean-Baptiste Regnault, The Origin of Painting (1785) or Karl Friedrich Schinkel, Origin of Painting (1830).

32 Mauro Carbone has insisted on the idea that any screen, in the sense of surface that retains images, needs a counter-screen, which filters these images. To him, these two screens form the basic structure of what he calls the arche-screen, i.e. the ideal object that exemplifies the conditions of possibility of a screen. See Carbone, $2016 \mathrm{~b}$.

33 Many early film theorists use the 'mirror' metaphor to designate the screen. See this example from 1907: 'Sitting before the white screen in a motion picture theatre we have the impression that we are watching true events, as if we were watching through a mirror following the action hurtling through space.' Papini, p. 48. 
possession-implies the passage to a new kind of action: what comes to the fore is a form of notation. The daughter draws a representation that retains what is otherwise temporary: thanks to the few lines that she jots down, she provides a substitute for her lover but also a record of his presence. This action triggers a change in the whole assemblage. With a new player (the young woman) comes a new orientation (towards permanence).

Indeed, the lines traced on the wall transform an extremely variable image into a defined profile. The shadow-like a cloud-is characterized by an extreme capriciousness: it can recall anything and everything. Notations, conversely, create steadiness: they capture one instant in a flow and eternalize it. Thanks to these lines, the wall also finds a stability as an element in this assemblage. It is no longer a fortuitous support; it becomes a stable fixture. Only an intentional erasure of the sketch drawn by the young girl could bring the wall back to its pristine status.

A notation does not imply that the image on the wall now pertains to the order of painting. The sketch is no longer a mobile and changing image as it was the shadow on the wall; nor is it yet an autonomous image whose meaning can be captured independently from its situation. What is drawn is a portrait but a portrait unable to detach itself from the portrayed. This is why Stoichita attributes to the image on the wall the quality of a ghost: it is something between two worlds. ${ }^{34}$ The same can be said of the wall: no longer an accidental support, it is not yet a dedicated space for one single and unique representation. It retains, but it does not secure. This fact can explain the difference between the screen and the canvas. The latter is a surface on which stability and permanence are granted; the former is a surface where a retention fights with a flow. The screen is a transitional object: like the young woman's sketch, it lies between two worlds.

This is when Butades, the father and the potter, makes his entrance. He takes some clay and following the lines on the wall he shapes a human form. He complements the sketch with more details, a relief, and colours. ${ }^{35}$ Then he detaches the mold from the wall and fires it with other pieces of pottery. Later, when his work is finished, he puts it in a temple. His action, which according Pliny marks the birth of portraiture, is deeply ambiguous.

34 'The silhouette traced by the young woman was only an eidolon, an image without substance, the intangible immaterial double of the one who was leaving', as opposed to the colossus, the statue which celebrated something which was “durable and alive"'. Stoichita, 1997, p. 20.

35 'Butades first invented the method of colouring plastic compositions, by adding red earth to the material, or else modelling them in red chalk'. Pliny the Elder, 35: 43. 
As father, Butades brings the portrait of the daughter's lover to its end, and in this way he fulfills his daughter's desire. At the same time, he truncates his daughter's romance: using the young man's profile for one of his works, he dismisses him as a lover and transforms him into a model. As a potter, Butades goes even further. Molding a statuette, he transforms a precarious drawing into a solid and "professional" work. In doing so, he creates an object that is no longer tied to a singular and personal situation but that can freely circulate, either as a commodity to be sold or as a relic to be revered. Not by chance the lover's portrait ends in a temple. The outcome of Butade's action is in a certain sense dramatic. The wall now is empty: it ceases to host either a shadow or a draft. Without traces, it is no longer a support. We have reached the end of the game.

What does Pliny's legend add to the basic elements that we have learned from Perseus's myth? Again, we follow the becoming-screen of a screen: it 'happens' that the wall is converted into a host for images. This becomingscreen takes place within an assemblage: the wall needs a number of other elements and actors in place if it is to work as a screen. The coordination of elements within this assemblage and their position in a particular spatial arrangement are the only means through which to produce and project a shadow on the wall. This shadow can also be the object of a notation. Yet this notation, in turn, elicits a change in the assemblage and the set of operations that it performs. Finally, the assemblage can collapse. When a notation becomes an independent object, it no longer needs a source or a support.

\section{Alberti's window}

'Let me tell you what I do when I'm painting. First of all, on the surface on which I'm going to paint, I draw a rectangle of whatever size I want, which I regard as an open window through which the subject to be painted is seen. ${ }^{36}$ The third scene I want to analyze is set in 1435, when Leon Battista Alberti famously describes the system of perspective in his De Pictura. ${ }^{37}$ The window metaphor would enjoy a broad appeal and apply not only to painting but also to narrative and finally to film - to say nothing of the

36 Alberti, p. 55 .

37 The first version of the book is in Italian and is entitled Della Pittura; an expanded Latin version is dated $1439-41$. 
present-day desktop of a computer operating system. ${ }^{8}$ Connected with the idea of the screen, Alberti's dispositive would highlight the propensity of a surface not only to host reflected or projected images, as Athena's shield and Butades's wall do, but also to frame an image, containing it within a border and organizing it in a composition. 39

In this vein, it is worthwhile to retrace how far Alberti goes with his metaphor. First, he recommends filling the rectangle with a number of lines that extend transversally, longitudinally, and backwards, all connected to a centric point. ${ }^{40}$ In this way, the window becomes a gridded space that can coherently map the scene that the painter intends to depict. Second, Alberti suggests the possibility of using a physical veil attached to a rectangular frame in order to simulate the presence of a window. ${ }^{41}$ The veil has to be gridded, this time with parallel squares, and the painter must look through it in order to locate individual objects within the field of vision as a whole, to define their mutual connections and to reduce their volume to flatness. He can then transfer the scene onto a similarly gridded sheet of paper or a canvas. ${ }^{42}$ Finally, Alberti states that a good painter does not need a physical

38 Émile Zola describes storytelling as a look through a window_-on a screen! —in his 'Lettre à Antony Valabrègue,' pp. 373-381. The metaphorical description of cinema as a window is especially developed by André Bazin in his essay, 'Theater and Cinema'. An early occurrence is in Italian film theories: "[At the cinema] what matters is feeling calmly as if one is an indifferent spectator, as if at the window, of whom neither intelligence of judgment, nor the exertion of observation, nor the nuisance of investigation is required.' Panteo. The continuity of the metaphor from Alberti to the computer culture is underscored in Friedberg.

39 It is in this capacity that the window would identify the screen as such, as in Friedberg 2006.

40 'I decide how large I wish the human figures in the painting to be. I divide the height of this man into three parts, which will be proportional to the measure commonly called a braccio. [...] With this measure I divide the bottom line of my rectangle into as many parts as it will hold; and this bottom line of the rectangle is for me proportional to the next transverse equidistant quantity seen on the pavement. Then I establish a point in the rectangle wherever I wish; and as it occupies the place where the centric ray strikes, I shall call this the centric point. [...] Having placed the centric point, I draw straight lines from it to each of the divisions on the base line.' Alberti, p. 55 . 41 'A veil loosely woven of fine thread, dyed whatever colour you please, divided up by thicker threads into as many parallel square sections as you like, and stretched on a frame. I set this up between the eye and the object to be represented, so that the visual pyramid passes through the loose weave of the veil.' Alberti, p. 69.

42 'This intersection of the veil has many advantages, first of all because [...] the object seen will always keep the same appearance. A further advantage is that the position of the outlines and the boundaries of the surface can easily be established accurately on the painting panel; for just as you see the forehead in one parallel, the nose in the next, the cheeks in another, the chin in one below, and everything else in its particular place, so you can situate precisely all the features on the panel or wall which you have similarly divided into appropriate parallels. Lastly, this veil affords the greatest assistance in executing your picture, since you can see any object that is round and in relief, represented on the flat surface of the veil.' Alberti, p. 69 . 
veil; it suffices that he imagines one in his field of vision, and then he can execute the painting according to it. ${ }^{43}$

Alberti's three steps are all aimed at improving the process of notation. ${ }^{44}$ Architectural windows are not neutral objects: they always mediate our view of the world. Alberti's window makes room for a more sophisticated mediation or, if you like, for a remediation of previous ways of looking: it elicits a sight indissolubly tied to the production of paintings that reiterate the same spatial organization of the world and that consequently acquire the nature of reliable visual data.

To embrace a process of notation to this extent has a consequence. What at first appearance was just a metaphor becomes a very precise set of tools. The window becomes a gridded rectangle, then a stretched and gridded veil, and finally a template that helps an artist perform the correct distribution of elements within the depicted scene. These tools are functional: they are purpose-built devices that respond to a precise task in an unequivocal and specific way. They are interchangeable: the painter can switch from one tool to another and combine them in a more effective complex. They impart precise instructions: they entail coordinated manual, optical and mental actions. Finally, these tools are replicable and improvable: the painter can easily find a veil or draft a rectangle or imagine a grid; and he can build a square wooden frame and add to it an eyepiece set from which to watch the scene at a fixed distance in a more accurate and uniform way. In other words, these tools are technical devices in a proper sense, inserted in a process of production and able to perform a range of tasks and generate a range of objects.

Alberti's metaphor and its avatars showcase their potentialities even better if we look at them against the backdrop of what is the true inaugural moment of perspective. I am referring here to Brunelleschi, the dedicatee of Alberti's De Pictura, who had a few years earlier offered a complementary experiment. He created a panel painted with the exterior of Florence's Baptistery as seen on a mirror placed three braccia inside the main entrance of the Cathedral. 'He painted it with such care and delicacy and with such great precision in the black and white colours of the marble that no miniaturist could have done it better. ${ }^{45}$ The only part he did not paint was

43 'Should they [some painters] wish to try their talents without the veil, they should imitate this system of parallels with the eye, so that they always imagine a horizontal line cut by another perpendicular at the point where they establish in the picture the edge of the object they observe.' Alberti, p. 69.

44 See Panofsky and Baxandall.

45 Manetti, p. 44. 
the sky: the panel contained instead a burnished silver, 'so that the real air and atmosphere were reflected in it, and thus the clouds seen in the silver are carried along by the wind as it blows'. The panel was pierced at the centre with a peephole, placed in coincidence with the point of view from which the Baptistery was seen by the painter. Whoever wanted to test the experiment had to stand at the same point on which the panel was painted, to look through the hole on the back of the panel, and to hold a flat mirror with the other hand in such a way that the painting would be reflected on it. The panel and the mirror had to cover the real Baptistery in such a way that the observer was just seeing the reflected panel. 'With the aforementioned elements of the burnished silver, the piazza, the viewpoint, etc., the spectator felt he saw the actual scene when he looked at the painting. ${ }^{46}$

Brunelleschi's device is quite convoluted. It assembles a pierced panel containing a depiction of an iconic Florentine building, a burnished surface, and a mirror designed to reflect both the panel and the reflection created by the burnished silver. It combines some of the elements that we have already encountered: it includes sources that 'cast' light and images - the sky, the panel — and a target that 'reflects' what hits it — the mirror. It requires users to perform a very precise action: they must keep the panel and the mirror aligned against the depicted building. It is also site-specific: whoever wants to enjoy the experiment is asked to stand on an exact point and to orient the panel and the mirror towards the real San Giovanni, hiding the building with the two devices in such a way that the image depicted on the panel and reflected on the mirror can substitute the building as actually seen. ${ }^{47}$ Finally, the purpose of Brunelleschi's device is a twofold amazement. On the one hand, spectators can appreciate the force of images so well designed that they look like reality. They can enjoy the substitution of reality with its representation..$^{4}$ On the other hand, if Brunelleschi's spectators keep their eye on the hole but remove the mirror and look at the real Baptistery, they can enjoy a game of peekaboo with the world.

46 Ibid. Brunelleschi's experiment raised many varying interpretations. Among them, Samuel Y. Edgerton offers a religious reading, tied to St. Paul's epistle to Corinthians, in The Mirror, The Window, and the Telescope, pp. 34-35 and 52-53. On the contrary, Friedrich Teja Bach finds a Platonic background in 'Filippo Brunelleschi and the Fat Woodcarver'.

47 The site-specificity is strongly suggested by Edgerton, 2006, pp. 51-52.

48 It is a pleasure that modern optical media would extensively exploit. Edgar Morin correctly recalls the fact that early spectators were flocking into temporary movie theaters not because they were anxious to know new pieces of the world but because they were astonished by the reduction of the world to image. See Morin. 
Compared with Brunelleschi's device, Alberti's window and its avatars retain the characteristics of an assemblage of tools and practices and the same time enjoy huge advantages. First, they are lighter. Alberti's dispositive meets a decisive simplification: it becomes a gridded surface that organizes the painting's composition, whatever its form - the ethereal surface of the window, a gridded paper or canvas, a transparent veil, a mere template, or all these things together. Second, Alberti's dispositive frees itself from the constraints of site-specificity. The window and the veil can be mounted any where, and they are ready to intercept any kind of reality. Third, and more radically, Alberti's dispositive is subjected to a process of internalization: the window and the veil can become a mental template and work 'inside the mind' of the painter, so to speak. The dispositive still assembles physical and virtual objects, practices, and situations: yet the assemblage is condensed and made ubiquitous in order to become more and more effective.

Lightness, ubiquity, and internalization are the ultimate characteristics that distinguish Alberti's window not only from Brunelleschi's experiment-which is its immediate reference-but also from Athena's shield and Butades's wall. These characteristics make Alberti's dispositive or assemblage a 'technical object' that has reached a more advanced stage in the process of individuation, to use Gilbert Simondon's term. ${ }^{49}$ In other words, Alberti's assemblage is a 'machine' able to fully express its mode of working, to the point that its individual components can be replaced and the whole can still operate, and in different situations. This does not mean that the previous devices did not possess their own identity - a detectable 'technical essence', again in Simondon's words. Rather, they were simply far from the phase of consolidation that Alberti's window fulfilled.

\section{Becoming-screen}

Not one of the primal scenes that I discussed is an ancestor of contemporary dispositives in a strict sense. There is no direct lineage between these prefigurations and our current screens: if we call the three episodes 'primal scenes', it happens in the framework of a preposterous temporality in which a 'pre-' surfaces as an effect of a 'post-'. Yet these primal scenes-and others that I could have added, including Plato's cave and prehistoric cave paintings, both of which are frequently associated with cinema-offer some useful 
suggestions..$^{50}$ This is not because they 'are like', 'caused', or 'led to' the definition of a screen today but because they problematize it.

In particular, these stories teach us that we cannot delineate a screen 'as such', as if it were a freestanding and self-contained device existing independently of its context. A screen always materializes as part of a dispositive; it becomes a screen in the framework of an assemblage of objects, needs, practices, actors, and circumstances that produce it as a screen. Habitual exposure to a screen may well have a naturalizing effect, causing the process underpinning its production to withdraw from perception. Yet what is always at stake is a convergence of elements that make it literally emerge. This emergence does not result from a straightforward historical causality but rather responds to contingencies and conjunctures. It does not follow a well-defined path but a route marked by digressions, impasses, and intersections. Once an assemblage is established, it can define its elements' functions and roles-a screen can become 'a' screen and 'this' screen. It can even simply 'be' a screen before the situation in which it operates reactivates the process of becoming-screen as its basic condition of existence.

In this process of becoming-screen, our stories underscore some recurring steps. First, the emergence of screen is always a conversion. There are objects (a shield, a wall, and a piece of paper or a canvas) that exploit some of their characteristics in order to acquire a new aptitude. This new propensity, which comes to the fore under the pressure of circumstances (in our stories, respectively, these pressures are a deadly gaze, an impending goodbye, and a desire to record visual data), elicits a re-arrangement of the elements at hand and, at the same time, it finds a decisive support in the assemblage that takes shape in the new situation. Everything within this field of emergence — including elements borrowed from outside - converge toward, and become functional to, the presence of the screen..$^{11}$

Second, the consolidation of the assemblage discloses a complex ecology of operations that underpin the screen's existence..$^{2}$ This ecology includes

50 On Plato's cave as a model for cinema, see Lapierre. The parallel became a pivotal issue in Jean Louis Baudry's essay 'Le Dispositif'. For a discussion on caves' paintings, see a recent and comprehensive discussion in Cometa.

51 On the components' transfer from one dispositive to another, see Simondon. The process of transference recalls here the concept of de- and re-territorialization in Deleuze and Guattari. See also the concept of re-location and the coincidence of persistence and difference that it allows in Casetti.

$5^{2}$ The concept of 'ecology of operation', an elaboration of Harun Farocki's idea of 'operational images', was first developed by Bernard Geoghegan in his 'Vision, Territory, Attention: the Birth of Digital Screens from Radar,' forthcoming. 
several spheres of action: it simultaneously invests technological tools, human behaviors, environmental elements, material objects, normative discourses, interpersonal exchanges, and forms of imaginations. The ways in which the different domains are addressed and interconnected vary: in Perseus's myth, the operations have to do with the tools and tactics of a warrior; in Boutades's legend, they involve the desires and ruses of a lover; in Alberti's account, they invest the skills and performances of a professional painter. Whatever the field of application, these operations define the range and extension of the assemblage of which the screen is part-whether it is contained or expanded, temporary or permanent. Through their performances, these operations also expose the assemblage's way of working - including its orientations and propensities. Finally, the variety of these operations can reveal the presence of internal conflicts or misalignments, with the emergence of points of contradictions. The screen is the pivotal elements that keep together the whole set of operations.

Third, our three examples uncover a recurring tendency to convert the screen into an optical dispositive. Surfaces that previously were aimed at other purposes - in particular, at shielding a warrior, at sheltering a couple of lovers, and at filtering the external world - become either the receptacle of reflected images (Athena's shield), the target of projection (Boutades's wall), or the set of tools that will generate and frame representations (Alberti's canvas and veil). Such a tendency recalls the transformation of the meaning of screen between the eighteenth and nineteenth centuries: what was first identified as a device for warding off the heat of a fire or a draft of air, or for dividing a room, or for hiding an object became a surface that addressed the eye and implied visual data. Rudiger Campe, in his essay included in this book, explores at length how, in early modern German culture, the word schirm moved from the idea of protection to the idea of display. We can detect the same tendency in the English screen, the French écran, or the Italian schermo. Our three examples underscore how the optical connotation of the term 'screen' is not a historical universal. Instead, it is an option that stems from a set of contingent needs, which in turn reflect a cultural orientation (the role of visuality either in the Classical or the Modern). The assemblage embodies this option, reorienting its components and its operations - even when they primarily imply hands and legs and not eyes, as in Perseus's myth.

Fourth, visuality is not uncontaminated. On the contrary, it still resonates with screen's previous functions. Athena's shield keeps protecting Perseus also when it becomes a reflecting surface. The wall on which the boy's shadow is projected preserves some physical intimacy to the two lovers. 
The veil through which the painter looks at the world continues to be a filter that sieves reality. The screen associates the looking-at-ness to other, older orientations. Moreover, the optical dimension is always connected with a space. Athena's shield guides Perseus's footsteps towards his target; Boutades's wall requires that the lamp and the lover be well aligned in order to produce shadows; Alberti's window, while transforming a landscape into a notation, defines the observer's vantage point. Screens are also spatial devices. In particular, they define the way in which the visible is distributed, to use Jacques Rancière's felicitous term..$^{53}$ In doing so, screens create points of access and blind spots, spaces of communality and seclusion; they coordinate the element at stake in order to either enhance or to dissipate visibility; and, finally, they define their own allocation. In short, they build the terrain-a playground or a battlefield, depending on the situation - upon which any action, including the act of seeing, becomes possible. In this sense, a screen is always part of a screenscape - a physical site innervated and catalyzed by the presence of a surface that hosts impermanent images, aimed at offering a mediation with the world and the others thanks to both the images that it hosts and its very nature of site.

A conversion, an assemblage, an ecology of operations, an optical dimension, and an environment. Despite their persistence and recursiveness, these steps do not fulfill all the conditions of the existence of screens - which in their entirety become apparent only at the moment of each screen's emergence, in connections with the contingencies and conjunctures that make that emergence possible. In the same vein, these steps do not sketch a unique model of the screen, as it were an object characterized by a well-established set of features. What these steps do is to unearth some of the key passages that every screen develops in its own way-a chain of procedures and occurrences that do not have the cogence of a formal syntax and that nevertheless disclose the backdrop from which a screen emerges and consolidates. In other words, the characteristics here envisioned, more than providing a 'definition' of what a screen is and must be, depict the 'ground' from which a screen surfaces-a 'ground' ready to give way to a specific 'form' but where forms are still in formation. ${ }^{44}$ Borrowing again Simondon's terms, these characteristics are sparks of a 'technical essence' that each screen would develop along different stages of individuation and often along alternative paths, on a playground that nevertheless is perceived as largely common to all screens.

54 On the interplay of figure and ground against which technical inventions emerge, see the illuminating passage by Simondon, pp. 59-62. 
In this sense, and only in this sense, the steps that we met in all our stories can illuminate how a screen becomes a screen-whatever its substance, from a bank of fog to the hypnotist's hand, from a building's façade to a painter's canvas. ${ }^{55}$ They also explain why and how we can envision a general idea of screen that encompasses screens' different instantiations-an arche-screen, to use Mauro Carbone's term, to be taken more as a matrix than as a model. $5^{6}$ Finally, these steps can illuminate how the idea of a screen can suddenly change - as happened at the very beginning of the nineteenth century, when the screen assumed its current dominant optical connotation at the expense of previous meanings focused on the capacity of filtering, sheltering, or hiding an external element, and as is happening now, when touch screens or immersive screens move our sensorium away from the mere sight.

This is why our primal scenes are significant. They show, retrospectively, how, where, and when screens can make an entrance. Indeed, their common nature is to stage a drama - whether through a myth, a legend, or a treatise. All together, they do not display a coherent and linear plot; on the contrary, they preserve differences, cracks, dissonances. In doing so, they suggest to us the means by which we can capture connections without obligations, developments without finality, and, moreover, histories without lineages. Simple stories, yet telling and exemplary: this is why they matter.

\section{Works Cited}

Alberti, Leon Battista. On Painting and On Sculpture. Edited by Cecil Grayson. London: Phaidon, 1972.

Baudry, Jean Louis. 'The Apparatus: Metapsychological Approaches to the Impression of Reality in the Cinema.' Camera Obscura 1 (Fall 1976): 104-26.

Baxandall, Michael. Painting and Experience in Fifteenth Century Italy. Oxford: Clarendon Press, 1972.

Bazin, André. 'Theater and Cinema.' In What is Cinema?, vol. 1, edited and translated by Hugh Gray, pp. 76-124. Berkeley: University of California Press, 1967.

Bettini, Maurizio. The Portrait of the Lover. Berkeley: University of California Press, 1999.

Caillois, Roger. Meduse et Cie. Paris: Gallimard, 1960.

Carbone, Mauro. Filosofia-schermi. Milano: Cortina, 2016. 
'Thematizing the arche-screen through its variations.' In Screens, edited by Dominique Chateau and José Moure, pp. 62-69. Amsterdam: Amsterdam University Press, 2016.

Casetti, Francesco. The Lumiére Galaxy: Seven Keywords for the Cinema to Come. New York: Columbia University Press, 2015.

Cometa, Michele. 'Surfaces profondes. Au-delà de l'écran dans les cultures visuelles paléolitiques.' In Des pouvoirs des écrans, edited by Mauro Carbone, Anna Caterina Dalmasso, and Jacopo Bodini, pp. 35-52. Milan: Mimésis, 2018.

Deleuze, Gilles. "What is a Dispositif?" In Two Regimes of Madness: Texts and Interviews 1975-1995, pp. 338-348. New York: Semiotext(e), 2006. Originally "Qu'est-ce qu'un dispositif?" In Deux régimes de fous: textes et entretiens 1975-1995, pp. 316-325. Paris: Éditions de Minuit, 2003.

—— and Felix Guattari. Anti-Oedipus: Capitalism and Schizophrenia. Translated by Robert Hurley, Mark Seem, and Helen R. Lane. New York: Viking Press, 1977. Derrida, Jacques. Memoirs of the Blind: The Self-Portrait and Other Ruins. Translated by Pascale-Anne Brault and Michael Naas. Chicago: University of Chicago Press, 1993 .

Edgerton, Samuel Y. The Mirror, The Window, and the Telescope. Ithaca: Cornell University Press, 2009.

Elsaesser, Thomas. Film History as Media Archaeology: Tracking Digital Cinema. Amsterdam: Amsterdam University Press, 2016.

Foucault, Michel. The Archaeology of Knowledge, Translated by A.M. Sheridan Smith. New York: Pantheon Books, 1972.

- - 'Nietzsche, Genealogy, History.' In Language, Counter-Memory, Practice: Selected Essays and Interviews, edited by D.F. Bouchard, pp. 139-164. Ithaca: Cornell University Press, 1977.

Freud, Sigmund. 'Medusa's Head.' In Sexuality and the Psychology of Love, edited by Philip Rieff, pp. 202-203. New York: Collier Books, 1993.

Friedberg, Anne. The Virtual Window: From Alberti to Microsoft. Cambridge, MA: The MIT Press, 2006.

Frontisi-Ducroux, Françoise and Jean-Pierre Vernant. Dans l'oeil du miroir. Paris: Odil Jacob, 1997.

Hesiod. Theogony. Works and Days. Testimonia. Edited and translated by Glenn W. Most. Loeb Classical Library 57. Cambridge, MA: Harvard University Press, 2007.

Huhtamo, Erkki and Jussi Parikka, eds. Media Archaeology: Approaches, Applications, and Implications. Berkeley: University of California Press, 2011.

Jameson, Frederic. The Prison-House of Language. Princeton: Princeton University Press, 1972. 
Kracauer, Siegfried. Theory of Film: The Redemption of Physical Reality. New York: Oxford University Press, 1960.

Lapierre, Marcel. Le cent visage du cinema. Paris: Grasset, 1948.

Latour, Bruno. 'Visualization and Cognition: Thinking with Eyes and Hands.' Knowledge and Society 6 (1986): 1-40.

Lindsay, Vachel. The Art of the Moving Picture. 2nd ed. New York: Macmillan, 1922. Luciani, Sebastiano Arturo. 'The Poetics of cinema.' In Early Film Theories in Italy: 1896-1922, edited by Francesco Casetti, Silvio Alovisio, and Luca Mazzei, pp. 329332. Amsterdam: Amsterdam University Press, 2017.

Manetti, Antonio di Tuccio. The Life of Brunelleschi. Edited and translated by Howard Saalman. University Park and London: The Pennsylvania State University Press, 1970.

The Monthly Magazine 87, June 1802.

Morin, Edgar. The Cinema, or, the Imaginary Man. Translated by Lorraine Mortimer. Minneapolis: University of Minnesota Press, 2005.

Moure, José. 'Archaic paradigms of the screen and its images.' In Screens: From Materiality to Spectatorship, edited by Dominique Chateau and José Moure, pp. 42-61. Amsterdam: Amsterdam University Press, 2016.

Ovid, Metamorphoses in Fifteen Books. Translated by the most eminent hands. Adorn'd with sculptures. London: Jacob Tonson, 1917. Available online through Eighteenth Century Collections Online. Ann Arbor: University of Michigan Library, 2007. http://name.umdl.umich.edu/o04871123.0001.ooo. Accessed July 2018.

The Oxford English Dictionary. Second Edition. Prepared by J.A. Simpson and E.S.C. Weiner. Oxford: Clarendon Press, 1989.

Panofsky, Erwin. Perspective as Symbolic Form. Translated by Christopher S. Wood. New York: Zone Books, 1991.

Panteo, Tullio, 'Il cinematografo,' La scena illustrata 19, no. 1 (October 1908).

Papini, Giovanni. 'The Philosophy of Cinematograph.' In Early Film Theories in Italy: 1896-1922, edited by Francesco Casetti, Silvio Alovisio, and Luca Mazzei, pp. 47-50. Amsterdam: Amsterdam University Press, 2017.

Parikka, Jussi. What is Media Archaeology? Cambridge, UK and Malden, MA: Polity Press, 2012.

Pausanias. Description of Greece. Translated by W.H.S. Jones. New York: G.P. Putnam Sons, 1918.

Pliny the Elder. The Natural History. Translated by John Bostock. London: Taylor and Francis, 1855 .

Rancière, Jacques. The Politics of Aesthetics. New York: Continuum, 2006.

The Repertory of Arts and Manufactures, vol. 16. London: Nichols and Son, 1802.

Siebers, Tobin. The Mirror of Medusa. Berkeley: University of California Press, 1983. 
Simondon, Gilbert. On the Mode of Existence of Technical Objects. Translated by Cécile Malaspina and John Rogove. Minneapolis: Univocal, 2017.

Stoichita, Victor I. A Short History of the Shadow. Translated by Anne-Marie Glasheen. London: Reaktion Books, 1997.

Teja Bach, Friedrich. 'Filippo Brunelleschi and the Fat Woodcarver.' Res: Anthropology and Aesthetics, $5^{1}$ (Spring 2007): 157-174.

Tille, Václav. 'Kinéma.' In Cinema All the Time: An Anthology of Czech Film Theory and Criticism, 1908-1939, edited by Jaroslav Anděl and Petr Szczepanik, pp. 71-91. Prague: National Film Archive, 2008.

Tomlinson, Gary. Culture and the Course of Human Evolution. Chicago: Chicago University Press, 2018.

Vernant, Jean Pierre. The Universe, the Gods, and Men. Translated by Linda Asher. New York: Harper Collins, 2001. Originally published as L'univers, les dieux, les homes. Paris: Seuil, 1999.

——. La mort dans les yeux. Paris: Hachette, 1985.

Zola, Émile. 'Lettre à Antony Valabrègue.' In Correspondance, pp. 373-381. Paris: Éditions du CNRS, 1978.

\section{About the Author}

Francesco Casetti is the Thomas E. Donnelly Professor of Humanities and Film and Media Studies at Yale University. He has previously taught in Italy where he served as president of the scholarly society of Film and Media Studies. He has also been visiting professor at Paris 3 La Sorbonne Nouvelle, at the University of Iowa, and at Harvard. His books include Inside the Gaze, Theories of Cinema, 1945-1995, Eye of the Century: Film, Experience, Modernity, and The Lumière Galaxy. Seven Key Words for the Cinema to Come, a study on the reconfiguration of cinema in a post-medium epoch. His current research focuses on two topics: the early film theories, especially the role of cinephobia; and a genealogy of screen that underlines its environmental aspects and the ways in which it becomes a component of our current 'mediascapes'. 